\title{
TWO INFANTS WITH BECKWITH-WIEDEMANN SYNDROME
}

\author{
Ratbi I ${ }^{1,2, *}$, Elalaoui $\mathrm{SC}^{1}$, Sefiani $\mathrm{A}^{1,2}$
}

*Corresponding Author: Ilham Ratbi, Department of Medical Genetics. National Institute of Health, Rabat, Morocco; 27 Avenue Ibn Battouta, B.P. 769, Rabat, Morocco; Tel.: +212(0)613-5867-97; Fax:+212(0)537-77-20-67; E-mail: ilhamratbi@yahoo.fr

\begin{abstract}
Beckwith-Wiedemann syndrome (BWS; OMIM $130650)$ is an overgrowth disorder characterized by macrosomia, macroglossia, organomegaly and developmental abnormalities (in particular abdominal wall defects with exomphalos) and a multi genetic disorder caused by dysregulation of genes expressed in the imprinted $11 \mathrm{p} 15$ chromosomal region. We report two unrelated male Moroccan firstborn infants who were hospitalized for macroglossia with breathing difficulties associated with other malformations indicative of BWS.
\end{abstract}

Keywords: Beckwith-Wiedemann syndrome (BWS), Newborn, Macroglossia, Overgrowth, Imprint

\section{INTRODUCTION}

Beckwith-Wiedemann syndrome (BWS, OMIM $130650)$ is a rare congenital growth disorder characterized by macrosomia, macroglossia, viscerome-

Department of Medical Genetics, National Institute of Health, Rabat, Morocco

2 Laboratory ofHuman Genomics, Faculty of Medicine and Pharmacy, University Mohammed V Souissi, Rabat, Morocco galy, embryonal tumors, midline abdominal wall defects, neonatal hypoglycemia and ear creases or ear pits, adrenocortical cytomegaly, and renal abnormalities [1-4]. It is estimated that BWS affects 1 in 13,700 newborns [5]. Most affected children do not have all of these symptoms, while other children have different findings such as hemihypertrophy, moderate/severe developmental delay, congenital heart defects, polydactyly and cleft palate [3]. Beckwith-Wiedemann syndrome is a multi genetic disorder caused by dysregulation of gene expression in the imprinted 11 p15 chromosomal region [6,7]. We report on two male Moroccan newborn infants hospitalized for macroglossia and breathing difficulties associated with other malformations characteristic of BWS.

\section{CASE REPORTS}

Patient 1. A 2-day-old male, firstborn infant of 25-year-old non consanguineous parents, was referred for medical genetics consultation because of multiple malformations. There was no family history of congenital anomalies. The mother had given birth prematurely by cesarean section at 34 weeks gestation because of hydramnios. The infant was intubated and ventilated for respiratory distress. He was macrosomic ( $>97$ th percentile) for length and weight, had facial dysmorphism of one infraorbital crease, mid 

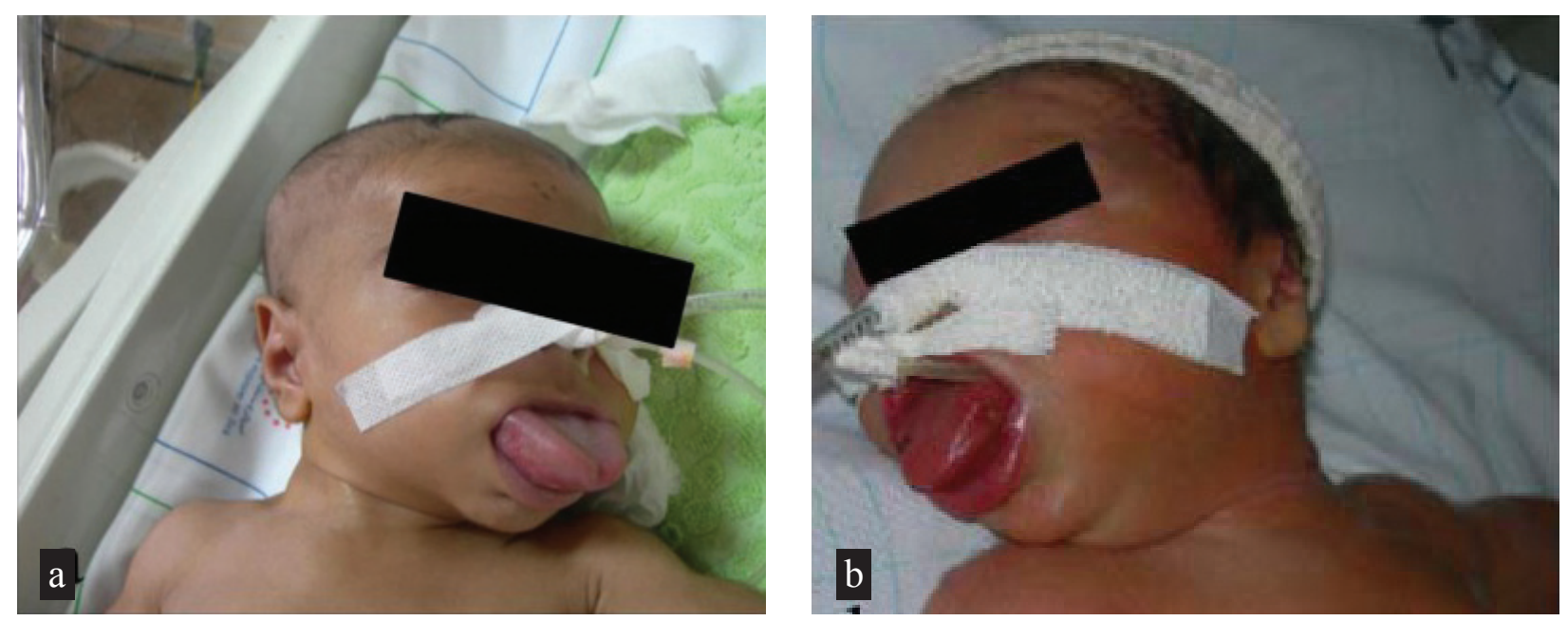

Figure 1: Photos of patient1 (a) patient 2 (b) with dysmorphic face and macroglossia.

face hypoplasia, macroglossia, low-set ears, distended abdomen and cryptorchidism (Figure 1a).

An abdomino-renal ultrasonography revealed nephromegaly with normal structure. All laboratory examinations were within normal limits, including blood glucose levels. The parents were healthy and appeared normal. We concluded from the association of hydramnios, prematurity, characteristic facies, macroglossia, overgrowth, and nephromegaly that the infant had BWS. Due to respiratory distress, the infant died when he was 7 days old.

Patient 2. A newborn male was hospitalized for multiple malformation syndrome and macroglossia responsible of respiratory distress. He was the firstborn of a healthy consanguineous couple (second degree), the mother being 20 years old and the father 27 years old at the time of birth. There was no relevant family history. The infant had been delivered by cesarean section at term because of suspected hydramnios. He had the same dysmorphic features as patient 1 . All laboratory examinations were within normal limits, including blood glucose levels. The chromosomal investigation revealed a normal male karyotype, $46 \mathrm{XY}$. We concluded that he had BWS because of the hydramnios, overgrowth ( $>97$ th percentile for length and weight), macroglossia and bilateral ureterohydronephrosis (Figure 1b).

\section{DISCUSSION}

Beckwith-Wiedemann syndrome is an overgrowth multiple malformation disorder [3] with a predisposition for developing embryonal tumors (most commonly Wilms' tumor or nephroblastoma). Its estimated prevalence [5] may be too low because of the marked variability in the syndome's presentation and the difficulties in diagnosis when the clinical features are less prominent and likely to be ignored [8]. Consensus diagnostic criteria for BWS do not exist, although it is generally accepted that diagnosis requires the presence of at least three characteristic findings, two major and one minor [3] (Table 1). Our patient 1 had three major and three minor signs, while patient 2 had two major and three minor signs. None of our patients had neonatal hypoglycemia, which is a minor criterion. Clinically, BWS must be distinguished from other overgrowth disorders, particularly the SimpsonGolabi-Behmel, the Sotos, the Weaver and the Perlman syndromes, each of which is characterized by distinctive facial features and other signs [9].

Eighty-five percent of BWS cases are sporadic, while $15 \%$ result from vertical transmission. Beckwith-Wiedemann syndrome is associated with abnormal transcription and regulation of genes in the imprinted domain on chromosome $11 \mathrm{p} 15.5$ $[6,7,10]$, which includes genes encoding growth factors and tumor suppressor genes. The paternally expressed genes (maternally imprinted) have growth enhancing activity and the maternally expressed genes (paternally imprinted) have growth suppressing activity. This region is organized into a telomeric domain which includes the IGF2 (Insulin Growth Factor II) and $\mathrm{H} 19$ genes, and a centromeric domain that includes the CDKNIC (Cyclin DependEnt Kinase Inhibitor 1C), KCNQ1 (potassium 
voltage-gated channel, subfamily $\mathrm{Q}$, member 1) and KCNQ1OT1 (KCNQ1-Overlapping transcript 1) genes. Each domain is controlled by its own imprinting center (IC1 and IC2 for the telomeric and centromeric domains, respectively) [7].

Beckwith-Wiedermann syndrome can be caused by a variety of defects. Cytogenetic abnormalities account for $1-2 \%$ of the cases and consist of maternally inherited translocations or inversions and trisomy with paternal duplication. Various molecular abnormalities in the $11 \mathrm{p} 15$ region have been reported [11-14]: 1) 11p15 paternal uniparental disomy (UPD), the maternal allele is lost and the paternal allele is duplicated. This occurs in approximately $20 \%$ of cases. 2) Mutations in the CDKNIC gene for a maternally expressed cell-cycle regulator occur in about $5 \%$ of patients [15]. The phenotype is typical and includes a very high frequency of exomphalos. Mutation of the CDKNIC gene account for $60 \%$ of familial BWS cases.
Epigenetic abnormalities also occur in BWS: 1) hypermethylation of the $H 19$ gene is found in $10 \%$ of cases. 2) Demethylation of $K v D M R$, a differentially methylated region at the 5 ' end of the KCNQ1OT1 gene, is involved in 55 to $60 \%$ of patients. The KCNQ1OT1 gene (also known as LITI or $K v L Q T 1-A S$ ) encodes an antisense transcript of the $K C N Q 1$ gene and is normally expressed from the paternal allele [15-19]. 3) Microdeletions within IC1 (H19 DMR) [20] or IC2 (Intermediate Chain 2) [21] account for some BWS cases with hypermethylation of H19 or demethylation of KCNQ1OT1.

Management of patients with BWS requires the surgical cure of exomphalos, monitoring and eventual treatment of hypoglycemia in the neonatal period, treatment of macroglossia, and screening for embryonal tumor. For patient 2, we recommended surgical treatment for his macroglossia at a future time and screening for an embryonal tumor. The risk of recurrence in a family depends on the genetic cause of BWS present in the proband.

Table 1. Diagnostic criteria for Beckwith-Wiedemann syndrome [4].

\begin{tabular}{|l|}
\hline The Presence of At Least Two Major and One Minor From the Following Features \\
\hline Major: \\
Positive family history (one or more family members with a clinical diagnosis of BWS, or \\
suggestive history and features) \\
Macrosomia \\
Anterior linear ear lobe creases/posterior helical ear pits \\
Macroglossia, omphalocele/umbilical hernia \\
Visceromegaly involving one or more intra-abdominal organs including liver, spleen, kidneys, \\
adrenal glands, and pancreas \\
Embryonal tumor (e.g., Wilms' tumor, hepatoblastoma, neuroblastoma, rhabdomyosarcoma) in \\
childhood \\
Hemyhyperplasia \\
Adrenocortical cytomegaly \\
Renal abnormalities including structural abnormalities, nephromegaly and nephrocalcinos \\
Cleft palate \\
Minor: \\
Polyhydramnios \\
Prematurity \\
Neonatal hypoglycemia \\
Facial nevus flammeus \\
Hemangioma \\
Characteristic facies including midfacial hypoplasia and infraorbital creases \\
Cardiomegaly, structural cardiac anomalies, cardiomyopathy (rare) \\
Diastasi recti \\
Advanced bone age \\
Monozygotic twinning disorder
\end{tabular}




\section{ACKNOWLEDGMENTS}

The authors have no financial or proprietary interest in any instrument or products used in this study. We would like to thank the patient's families. We are also grateful to Professors S. Kettani and Z. Ghanimi (Service de Réanimation Pédiatrique, Hôpital d'Enfants, Rabat, Morocco) for their help.

\section{REFERENCES}

1. Wiedemann HR. Familial malformation complex with umbilical hernia and macroglossia a "new syndrome"? (French). J Genet Hum 1964; 13: 223-232.

2. Pettenati MJ, Haines JL, Higgins RR, Wappner RS, Palmer CG, Weaver DD. WiedemannBeckwith syndrome: presentation of clinical and cytogenetic data on 22 new cases and review of the literature. Hum Genet 1986; 74(2): 143-154.

3. Elliott M, Bayly R, Cole T, Temple IK, Maher ER. Clinical features and natural history of Beckwith-Wiedemann syndrome: presentation of 74 new cases. Clin Genet 1994; 46(2): 168-174.

4. DeBaun MR, Tucker MA. Risk of cancer during the first four years of life in children from The Beckwith-Wiedemann Syndrome Registry. J Pediatr 1998; 132(3, Pt. 1): 398-400.

5. Thorburn MJ, Wright ES, Miller CG, SmithRead EH. Exomphalos-macroglossia-gigantism syndrome in Jamaican infants. Am J Dis Child 1970; 119(4): 316-321.

6. Maher ER, Reik W. Beckwith-Wiedemann syndrome: imprinting in clusters revisited. J Clin Invest 2000; 105(3): 247-252.

7. Reik W, Walter J. Genomic imprinting: parental influence on the genome. Nat Rev Genet 2001; 2(1): 21-32.

8. Sotelo-Avila C, Gonzalez-Crussi F, Fowler JW. Complete and incomplete forms of BeckwithWiedemann syndrome: their oncogenic potential. J Pediatr 1980; 96(1): 47-50.

9. Cohen MM Jr. Beckwith-Wiedemann syndrome: historical, clinicopathological, and etiopathogenetic perspectives. Pediatr Dev Pathol 2005; 8(3): 287-304.

10. DeBaun MR, Niemitz EL, McNeil DE, Brandenburg SA, Lee MP, Feinberg AP. Epigenetic alterations of H19 and LIT1 distinguish patients with Beckwith-Wiedemann syndrome with cancer and birth defects. Am J Hum Genet 2002; 70(3): 604-611.

11. Engel JR, Smallwood A, Harper A, Higgins MJ, Oshimura M, Reik W, Schofield PN, Maher ER. Epi-genotype-phenotype correlations in BeckwithWiedemann syndrome. J Med Genet 2000; 37(12): 921-926.

12. Bliek J, Maas SM, Ruijter JM, Hennekam RC, Alders M, Westerveld A, Mannens MM. Increased tumour risk for BWS patients correlates with aberrant H19 and not KCNQ1OT1 methylation: occurrence of KCNQ1OT1 hypomethylation in familial cases of BWS. Hum Mol Genet 2001; 10(5): 467-476.

13. Gaston V, Le Bouc Y, Soupre V, Burglen L, Donadieu J, Oro H, Audry G, Vazquez MP, Gicquel C. Analysis of the methylation status of the KCNQ1OT and H19 genes in leukocyte DNA for the diagnosis and prognosis of Beckwith-Wiedemann syndrome. Eur J Hum Genet 2001; 9(6): 409-418.

14. Weksberg R, Nishikawa J, Caluseriu O, Fei YL, Shuman C, Wei C, Steele L, Cameron J, Smith A, Ambus I, Li M, Ray PN, Sadowski P, Squire J. Tumor development in the Beckwith-Wiedemann syndrome is associated with a variety of constitutional molecular $11 \mathrm{p} 15$ alterations including imprinting defects of KCNQ1OT1. Hum Mol Genet 2001; 10(26): 2989-3000.

15. Lam WW, Hatada I, Ohishi S, Mukai T, Joyce JA, Cole TR, Donnai D, Reik W, Schofield PN, Maher ER. Analysis of germline CDKN1C (p57KIP2) mutations in familial and sporadic Beckwith-Wiedemann syndrome (BWS) provides a novel genotype-phenotype correlation. J Med Genet 1999; 36(7): 518-523.

16. Lee MP, DeBaun MR, Mitsuya K, Galonek HL, Brandenburg S, Oshimura M, Feinberg AP. Loss of imprinting of a paternally expressed transcript, with antisense orientation to KVLQT1, occurs frequently in Beckwith-Wiedemann syndrome and is independent of insulin-like growth factor II imprinting. Proc Natl Acad Sci USA 1999; 96(9): 5203-5208.

17. Smilinich NJ, Day CD, Fitzpatrick GV, Caldwell GM, Lossie AC, Cooper PR, Smallwood AC, Joyce JA, Schofield PN, Reik W, Nicholls RD, Weksberg R, Driscoll DJ, Maher ER, Shows TB, Higgins MJ. A maternally methylated $\mathrm{CpG}$ island 
in KvLQT1 is associated with an antisense paternal transcript and loss of imprinting in Beckwith-Wiedemann syndrome. Proc Natl Acad Sci USA 1999; 96(14): 8064-8069.

18. Cleary MA, van Raamsdonk CD, Levorse J, Zheng B, Bradley A, Tilghman SM. Disruption of an imprinted gene cluster by a targeted chromosomal translocation in mice. Nat Genet 2001; 29(1): 78-82.

19. Fitzpatrick GV, Soloway PD, Higgins MJ. Regional loss of imprinting and growth deficiency in mice with a targeted deletion of KvDMR1. Nat Genet 2002; 32(3): 426-31.

20. Sparago A, Cerrato F, Vernucci M, Ferrero GB, Silengo MC, Riccio A. Microdeletions in the human H19 DMR result in loss of IGF2 imprinting and Beckwith-Wiedemann syndrome. Nat Genet 2004; 36(9): 958-960.

21. Niemitz EL, DeBaun MR, Fallon J, Murakami K, Kugoh H, Oshimura M, Feinberg AP. Microdeletion of LIT1 in familial Beckwith-Wiedemann syndrome. Am J Hum Genet 2004; 75(5): 844-849. 
